\title{
Acute compartment syndrome in patients on long-term anticoagulation therapy.
} Matthew Mazur, Nour Jabaly, Nabil Ebraheim*

Department of Orthopedic Surgery, University of Toledo College of Medicine and Life Sciences, 3000 Arlington Ave, Toledo, Ohio, USA

\begin{abstract}
Development of acute compartment syndrome (ACS) poses problems for patients on long-term anticoagulation, who are at higher risk for hemorrhagic insult. The populations predisposed to ACS and long-term anticoagulation individually are quite different, making this a particularly unique population that has been rarely studied. Eight patients at our institution were included in this study based on development of ACS while being on long-term anticoagulation. Causes of ACS were almost evenly split between idiopathic, fracture, and blunt trauma without fracture. The most commonly involved compartment was the lower leg. ACS was appropriately diagnosed based on clinical assessment alone in all patients, based on heightened level of suspicion. All patients were treated with single- or double-incision fasciotomy, as is the standard of treatment in the general population. All patients experienced good outcomes post-fasciotomy with prompt bridging to anticoagulant regimen, with minimal complications and no cases of mortality. These patients were not revealed to have any identifiably unique risk factors for developing ACS, and they can be treated similarly to patients not on anticoagulation and adequately bridged to therapeutic anticoagulation levels.
\end{abstract}

Keywords: Anticoagulation, Acute compartment syndrome, Hemorrhagic, Trauma.

\section{Introduction}

Acute compartment syndrome (ACS) is a condition that occurs as a result of increased intracompartmental pressure (ICP) within an enclosed fascial space, reducing capillary perfusion to levels that can cause significant soft tissue ischemia [1]. ACS follows an initial insult, either traumatic or hemorrhagic, and can be classified based on its etiology as orthopedic (fracture or crush injury), vascular, iatrogenic, or soft tissue injury [2]. The forearm and leg are the most commonly affected sites, while the arm, hand, and foot are less commonly involved. Although ACS may develop more frequently in young adult males, its traumatic etiology spares no epidemiological group from being at risk [4]. Clinical diagnosis of ACS remains challenging, but is centered on physical exam findings supplemented with ICP measurements if necessary $[5,6]$. Timely diagnosis and intervention is essential in order to avoid complications including muscle contracture, neurological deficits, infection, and limb amputation $[7,8]$. Reduction of ICP via incision fasciotomy is the gold standard of treatment, and technique varies based on which compartment is involved as well as the surgeon's preference/experience $[9,10]$. Fasciotomy may be supplemented by temporary elevation of the affected limb or hyperbaric oxygen therapy [2,11-13]. Appropriate treatment of ACS provides favorable outcomes for most patients.

Long-term prophylactic anticoagulation therapy is utilized in patients with any one of several medical conditions including cardiac arrhythmia, venous thromboembolism (VTE), heart valve replacement, and hypercoagulable disorders for effective prevention of adverse outcomes such as arterial and venous thromboembolism [14-16]. Long-term anticoagulation is not uncommon in the United States, with treatment prevalence estimated at $5 \%$ of persons aged $65-74$ and greater than $10 \%$ of persons of age $\geq 75$ [17]. This therapy most frequently involves the use of vitamin $\mathrm{K}$ antagonists like warfarin (Coumadin), but treatment guidelines have recently expanded to include the option for use of newer direct coagulation factor inhibitors like Dabigatran, Lovenox, Apixaban, and Rivaroxiban [18-21]. Several large-scale studies have determined that although longterm anticoagulation therapy provides effective prophylaxis, it carries significant risk for hemorrhagic complications [2224]. Interestingly, few studies have thoroughly investigated how an increased risk for hemorrhage in patients on long-term anticoagulation may relate to development of ACS.

In this study we aimed to identify the proportion of patients treated for ACS at our institution that were on long-term anticoagulation therapy. We also examined these patients' epidemiological characteristics, treatment course, and clinical outcome.

\section{Materials and Methods}

A total of 392 patients were evaluated and treated for ACS between the years 2008-2018 at our academic institution with a level 1 trauma center. Patient information was obtained through electronic medical record access following institutional IRB approval. Of these patients, eight were on long-term anticoagulation prior to developing ACS. Patients were diagnosed with ACS clinically, without need for supplemental compartment pressure reading. All patients were treated surgically with single- or double- incision fasciotomy. Anticoagulation was stopped approximately 10 hours before 
surgery and patients were bridged to heparin. Heparin was continued during surgery and patients were restarted on prior anticoagulant dosing approximately 8-12 hours following surgery. Patients were followed up for at least 6 months following diagnosis and intervention.

Analysis of outcome after fasciotomy was performed using determinants suggested by the literature and internal standards. A "favorable" outcome was defined as limb salvage with or without dysfunction. An "unfavorable" outcome was defined as amputation or death of the patient. Statistical analysis was performed Fisher's Exact test and univariate logistic regression. The SAS system (SAS Institute Inc $\subset$, North Carolina, United States) was used for all data analyses.

\section{Results}

Out of 392 patients evaluated and treated for ACS between year 2008 and year 2018, eight were on an anticoagulation regimen at the time of treatment for ACS and met inclusion criteria for this study. The demographics for this population were six males and two females, with an average age of 69 years (range 4190). Causes of ACS included idiopathic (3 patients), fracture (3 patients), and blunt trauma without fracture (2 patients). Involved compartments were forearm (2), thigh (1), and lower leg (5) (Table 1).

Reasons for long-term anticoagulation were history of myocardial infarction (MI), atrial fibrillation (Afib), deep vein thrombosis (DVT), pulmonary embolism (PE), coronary artery stent, congestive heart failure $(\mathrm{CHF})$, to coronary artery disease (CAD). Only one patient did not have documentation of indication for long-term anticoagulation due to medical records outside of our system. Methods of anticoagulation were Warfarin (Coumadin), Enoxaparin (Lovenox), and Rivaroxaban (Xarelto) (Table 1).

Fasciotomy was performed an average of 10.65 hours (range 0-24) after identification of ACS. Surgical decompression methods were split evenly between single-incision (4 patients) and double incision (4 patients) fasciotomy. PT / INR levels at the time of operation was on average 19.6 (range: 13.6-35.7) / 1.66 (range: 0.99-3.47). Average follow-up time for these patients was 3.6 months. All patients had favorable outcomes of treatment. Three cases required no additional intervention, three required one irrigation and debridement, one required two debridements, and one required hematoma evacuation. All patients completed successful recoveries without complication or recurrence of ACS. There were no cases with associated limb loss or mortality. Statistical analysis was unable to reveal significance of outcome vs. age, gender, anticoagulation method, ACS location, or fasciotomy technique (Table 1).

\section{Discussion}

Compartment syndrome may occur in any muscle compartment within the body, and is most often seen in the forearm and lower leg. Common causes at these sites include fractures, blunt trauma, and external compression $[25,26]$. It is important to identify neurovascular structures in these areas as their compromise may provide important clinical clues for diagnosis.

The forearm is comprised of volar (flexor) and dorsal (extensor) compartments, as well as the flexor wad (Table 2). The anterior compartment contains the median nerve, deep branch of the radial nerve, as well as the ulnar nerve and artery. The posterior compartment contains the radial nerve and artery, posterior interosseous nerve and artery, radial recurrent artery, and profunda brachii artery. The lower leg is divided into four compartments (Table 3 ). The anterior compartment contains the deep fibular nerve, as well as the anterior tibial nerve, artery, and vein. The lateral compartment contains the superficial fibular nerve and the fibular artery. The superficial posterior compartment contains the tibial nerve, while the deep posterior compartment contains the tibial nerve and posterior tibial artery (and its branches).

Development of ACS in the thigh is less common than the forearm or lower leg but is associated with higher morbidity and mortality, likely due to the fact that many cases are caused by high-energy blunt trauma [27,28]. It is often seen secondary to femoral fractures, intramedullary femoral nailing, application of anti-shock trousers, compression or contusion, and extensive deep-venous thrombosis [29]. The thigh contains anterior, medial, and posterior compartments (Table 4). The anterior compartment contains the femoral nerve, artery, and veins. The saphenous nerve, a branch of the femoral nerve, provides sensation over the knee, medial leg, and foot. The posterior compartment contains the profunda femoris artery branches, and the sciatic nerve. The medial compartment contains the

Table 1. Summary of patient injury location, cause, and treatment course.

\begin{tabular}{|c|c|c|c|c|c|c|c|}
\hline Patient & ACS location & Cause of injury & Fasciotomy Technique & $\begin{array}{l}\text { Anticoagulation } \\
\text { therapy }\end{array}$ & Imaging & $\begin{array}{l}\text { INR / PT (at } \\
\text { operation) }\end{array}$ & Outcome \\
\hline 1 & Forearm & Puncture wound & $\begin{array}{l}\text { Single } 14 \mathrm{~cm} \text { volar } \\
\text { incision }\end{array}$ & Warfarin & x-ray of RT forearm & $35.7 / 3.47$ & Two debridements \\
\hline 2 & Thigh & $\begin{array}{l}\text { No injury. Missed } \\
\text { lovenox dose for } 1 \text { day }\end{array}$ & $\begin{array}{l}\text { Both lateral and medial } \\
\text { incisions, and standard } 2\end{array}$ & Lovenox & $\begin{array}{l}\text { None- was transferred } \\
\text { from previous hospital }\end{array}$ & $13.6 / 0.99$ & $\begin{array}{l}\text { Hematoma } \\
\text { evacuation }\end{array}$ \\
\hline 3 & Forearm & $\begin{array}{l}\text { Contusion while } \\
\text { moving boxes }\end{array}$ & Single volar incision & Coumadin & x-ray of shoulder & $20.3 / 1.73$ & One debridement \\
\hline 4 & Lower leg & MVA & $12 \mathrm{~cm}$ incision & Rivaroxaban & x-ray of leg & $16.3 / 1.30$ & One debridement \\
\hline 5 & Lower leg & Fall & $\begin{array}{l}10 \mathrm{~cm} \text { lateral incision and } \\
6 \mathrm{~cm} \text { medial incision }\end{array}$ & Warfarin & x-ray of leg & $16.5 / 1.31$ & Uneventful \\
\hline 6 & Lower leg & Hit by a car & 2 incisions & Coumadin & x-ray of leg & $18.4 / 1.52$ & One debridement \\
\hline 7 & Lower leg & Fall & Anterolateral incision & Rivaroxaban & x-ray of leg & $14.7 / 1.14$ & Uneventful \\
\hline 8 & Lower leg & $\begin{array}{l}\text { Leg pinched between a } \\
\text { wall and lawn mower }\end{array}$ & $\begin{array}{l}15 \mathrm{~cm} \text { lateral incision } \\
\text { and } 8 \mathrm{~cm} \text { medial incision }\end{array}$ & Coumadin & x-ray of leg & $21.3 / 1.85$ & Uneventful \\
\hline
\end{tabular}


Table 2. Important structures within the forearm compartments.

\begin{tabular}{|c|c|c|c|}
\hline \multirow{2}{*}{ Structure } & \multicolumn{2}{|l|}{ Forearm Compartments } & \multirow[b]{2}{*}{ Mobile Wad } \\
\hline & Volar & Dorsal & \\
\hline \multirow[t]{9}{*}{ Muscles } & Flexor carpi ulnaris m. & Extensor digitorum $\mathrm{m}$. & Extensor carpi radialis longus $\mathrm{m}$. \\
\hline & Palmaris longus $\mathrm{m}$. & Extensor digiti minimi m. & Extensor carpi radialis brevis $\mathrm{m}$. \\
\hline & Flexor carpi radialis $\mathrm{m}$. & Extensor carpi ulnaris $\mathrm{m}$. & Brachioradialis $\mathrm{m}$. \\
\hline & Pronator teres $\mathrm{m}$. & Anconeus m. & \\
\hline & Flexor digitorum superficialis m. & Supinator $\mathrm{m}$. & \\
\hline & Flexor digitorum profundus $\mathrm{m}$. & Abductor pollicis longus $\mathrm{m}$. & \\
\hline & Flexor pollicis longus $\mathrm{m}$. & Extensor pollicis longus $\mathrm{m}$. & \\
\hline & \multirow[t]{2}{*}{ Pronator quadratus $\mathrm{m}$. } & Extensor pollicis brevis $\mathrm{m}$. & \\
\hline & & Extensor indices $\mathrm{m}$. & \\
\hline \multirow[t]{3}{*}{ Nerves } & Median n. (and anterior interosseous branch) & Radial $\mathrm{n}$. & \\
\hline & Ulnar $\mathrm{n}$. & \multirow[t]{2}{*}{ Posterior interosseous $\mathrm{n}$. } & \\
\hline & Deep branch of radial $\mathrm{n}$. & & \\
\hline \multirow[t]{3}{*}{ Vessels } & \multirow[t]{3}{*}{ Ulnar a. } & Radial a. & \\
\hline & & Posterior interosseous a. & \\
\hline & & Profunda brachii a. & \\
\hline
\end{tabular}

Table 3. Important structures within the lower leg compartments.

\begin{tabular}{|c|c|c|c|c|}
\hline \multirow{2}{*}{ Structure } & \multicolumn{3}{|c|}{ Lower Leg Compartments } \\
\cline { 2 - 4 } & Anterior & Lateral & Superficial Posterior & Deep Posterior \\
\hline \multirow{2}{*}{ Muscles } & Tibialis anterior $\mathrm{m}$. & Peroneus longus $\mathrm{m}$. & Gastrocnemius $\mathrm{m}$. & Tibialis posterior $\mathrm{m}$. \\
\cline { 2 - 5 } & Extensor hallucis longus $\mathrm{m}$. & Peroneus brevis $\mathrm{m}$. & Soleus $\mathrm{m}$. & Flexor hallucis longus $\mathrm{m}$. \\
\cline { 2 - 5 } & Extensor digitorum longus $\mathrm{m}$. & & Plantaris $\mathrm{m}$. & Flexor digitorum longus $\mathrm{m}$. \\
\hline Nerves & Deep peroneal $\mathrm{n}$. & Common peroneal $\mathrm{n}$. & & Tibial $\mathrm{n}$. \\
\hline Vessels & Anterior tibial artery and veins & & & Peroneal artery and vein \\
\hline
\end{tabular}

Table 4. Important structures within the thigh compartments.

\begin{tabular}{|c|c|c|c|}
\hline \multirow[t]{2}{*}{ Structure } & \multicolumn{3}{|c|}{ Thigh Compartments } \\
\hline & Anterior & Medial & Posterior \\
\hline \multirow[t]{8}{*}{ Muscles } & Sartorius $\mathrm{m}$. & Gracilis m. & Biceps femoris $\mathrm{m}$. \\
\hline & Rectus femoris $\mathrm{m}$. & Adductor longus $\mathrm{m}$. & Semitendinosus $\mathrm{m}$. \\
\hline & Vastus lateralis $\mathrm{m}$. & Adductor brevis $\mathrm{m}$. & Semimembranosus $\mathrm{m}$. \\
\hline & Vastus intermedius $\mathrm{m}$. & Adductor magnus m. & \\
\hline & Vastus medialis $\mathrm{m}$. & Pectineus $\mathrm{m}$. & \\
\hline & Flexor digitorum profundus $\mathrm{m}$. & & \\
\hline & Flexor pollicis longus $\mathrm{m}$. & & \\
\hline & Pronator quadratus $\mathrm{m}$. & & \\
\hline Nerves & Femoral $\mathrm{n}$. & Obturator $\mathrm{n}$. & Sciatic $\mathrm{n}$. \\
\hline \multirow[t]{2}{*}{ Vessels } & Femoral artery and vein & Obturator artery and vein & Profunda femoris artery branches \\
\hline & & Profunda femoris a. & \\
\hline
\end{tabular}

profunda femoris artery, obturator artery and vein, and the obturator nerve.

Diagnosis of acute compartment syndrome is typically made based on a thorough clinical examination. Assessment of the "6 P's" (pain, poikilothermia, pallor, paresthesia, pulselessness and paralysis) provides crucial information to identify a diagnosis of compartment syndrome [30]. Patients most often present with symptoms of aching or burning pain that may be disproportionate to the injury, which can occasionally have associated paresthesia. Cardinal physical exam signs are an associated tense compartment and motor deficits in the affected limb $[31,32]$. Measurement of ICP in the suspected compartment is used as a supplemental diagnostic tool for cases that are not diagnosed clinically. There are several diagnostic ICP measurement protocols used, but in the prevailing technique an ICP within $30 \mathrm{mmHg}$ of diastolic blood pressure is an indication of ACS and signals a need for surgical intervention [33]. Incidentally, all patients in this study were diagnosed with compartment syndrome based on clinical findings alone without the need for ICP measurement.

Timely treatment of ACS via fasciotomy can allow for good functional outcomes, but surgical outcomes are not always favorable. Fasciotomy carries up to a $15 \%$ mortality rate and $21 \%$ amputation rate, with risk for other morbidities as well $[34,35]$. There is limited consensus on whether to use one- vs. two-incision fasciotomy technique for optimization of surgical outcomes. Forearm compartment syndrome is typically treated with a single volar incision, starting $1 \mathrm{~cm}$ proximal and 2 $\mathrm{cm}$ lateral to the medial epicondyle and crossing obliquely across the antecubital fossa and over the volar aspect of the mobile wad. Other surgical options include an ulnar incision beginning radial to the flexor carpi ulnaris and extending to the medial epicondyle of the humerus, as well as a zigzag incision [36]. Both cases of forearm ACS in this study were treated successfully with a single volar incision. In ACS of the lower leg, all four compartments should be decompressed either via 
two separate incisions (one anterolateral and one posteromedial) or one lateral incision, however, neither technique has been shown to be superior to the other [37]. Cases of lower leg ACS in this study were successfully treated with both single- and double-incision techniques. ACS of the thigh has typically been addressed with decompression of the anterior and posterior compartments with a single lateral incision. With lateral and posterior compartment syndromes, the skin and subcutaneous tissues are incised beginning and around the intertrochanteric line and extending to the lateral epicondyle. Afterwards, the iliotibial band and fascia over the vastus lateralis are divided lengthwise. The adductor muscle group can be released through a separate longitudinal incision if necessary [38]. The one case of thigh ACS in this study was surgically treated with twoincision, four-compartment fasciotomy.

There have been relatively few studies investigating the development of ACS in patients on long-term anticoagulation therapy and subsequent management. It is a particularly unique patient population because while younger patients experience ACS at a higher rate, long-term anticoagulation is much more common in the elderly. Accordingly, this study's population was on average older, with no patient younger than 40 years of age. Clinical suspicion for ACS should be higher in patients on long-term anticoagulation, as they are at a higher risk for bleeding and should be monitored for development of any symptoms concerning for compartment syndrome. For example, development of compartment syndrome in a patient on anticoagulation has been documented following something as simple as venipuncture [39]. Based on this heightened suspicion, all cases in this study were appropriately diagnosed based on clinical exam, without the need for ICP measurement. Causes of ACS were almost equally divided between idiopathic, fracture, and blunt trauma without fracture. The most common compartments affected in the patients within this study were the lower leg and forearm respectively. Both the causes of ACS as well as the affected compartments were consistent with trends from the general population $[2,3]$.

All patients in this study experienced favorable outcomes following decompression with well-known fasciotomy techniques, dismissing the need for specialized techniques in these cases. Patients were able to tolerate emergent fasciotomy with average INR slightly above the level of 1.5 recommended for elective procedures [40-44]. The risk of hemorrhagic complications was notably low, even as the patients were promptly bridged back onto prior anticoagulation regimen following surgery.

This study had some limitations, most notably small sample size. This population of patients is particularly unique, which limits the amount of case data available to include. In turn, the small sample size made determination of any statistical significance difficult. Additionally, it is impossible to know if these patients presented for further treatment at outside hospitals which could limit our understanding of lifetime risk in these patients. Finally, some patient data was not able to be reported (and was noted as such) due to incomplete charting.

\section{Conclusion}

Patients on long-term anticoagulation therapy benefit most from surgical intervention in the case of acute compartment syndrome (ACS). Causes of ACS as well as frequency of involved compartments were consistent with the general population. With a higher index of suspicion for hemorrhagic complications in these patients, clinical assessment is sufficient to diagnose ACS. All the patients included in this study underwent fasciotomy decompression in locations of the thigh, lower leg, or forearm. In all cases emergent fasciotomy was performed due to the life-threatening characteristics of these cases. The mortality rate for patients who had fasciotomy was noticeably low, and the surgical outcome was favorable in all of the cases. With appropriate follow-up, infectious and hemorrhagic complications were notably minimized. All patients regained full strength and movement in their affected limbs after physical therapy and continuous follow up at the orthopedic department.

\section{References}

1. Mubarak SJ, Hargens AR. Acute compartment syndromes. Surg Clin North Am. 1983;63:539-65.

2. Tiwari A, Haq AI, Myint F, et al. Acute compartment syndromes. British J Surg. 2002;89(4):397-412.

3. Via AG, Oliva F, Spoliti M, et al. Acute compartment syndrome. Muscles ligaments tendons J. 2015;5(1):18.

4. McQueen MM, Gaston P, Court-Brown CM. Acute compartment syndrome: who is at risk? J Bone Joint Surg Br. 2000;82(2):200-203.

5. Shadgan B, Menon M, O'brien PJ, et al. Diagnostic techniques in acute compartment syndrome of the leg. J Orthopaedic Trauma. 2008;22(8):581-87.

6. McQueen MM, Court-Brown CM. Compartment monitoring in tibial fractures: the pressure threshold for decompression. J Bone Joint Surg Br. 1996;78(1):99-104.

7. Mlibarak SJ, garetto IP, Akeson WH. (1978). Acute Compartment Syndromes: Diagnosis and Treatment with the Aid of the Wick Catheter.

8. Jensen SL, Sandermann J. Compartment syndrome and fasciotomy in vascular surgery. A review of 57 cases. Eur J Vasc Endovasc Surg. 1997;13(1):48-53.

9. Tiwari A, Haq AI, Myint F, et al. (2002). Acute compartment syndromes. Br J Surg. 2002;89(4):397-412.

10. Sheridan GW. (1976). Fasciotomy in the treatment of the acute compartment syndrome. J Bone Joint Surg Am. 1976;58(1):112-115.

11. Mubarak SJ, Owen CA. (1977). Double-incision fasciotomy of the leg for decompression in compartment syndromes. $\mathrm{J}$ Bone Joint Surg. 1977;59(2):184-187.

12. Tiwari A, Haq AI, Myint F, et al. Acute compartment syndromes. Br J Surg, 2002;89(4):397-412.

13. Chidgey LK, Szabo RM, Kolack B. Effects of elevation on nerve function in an acute upper extremity nerve compression model. J Orthopaedic Res. 1989;7(6):783-91.

14. Bouachour G, Cronier P, Gouello JP, et al. Hyperbaric oxygen therapy in the management of crush injuries: a 
randomized double-blind placebo-controlled clinical trial. J Trauma Acute Care Surg. 1996;41(2):333-39.

15. Wattel F, Mathieu D, Neviere R, et al. Acute peripheral ischaemia and compartment syndromes: a role for hyperbaric oxygenation. Anesth. 1998;53(S2):63-5.

16. Wright IS, Bourgain RH, Foley WT, et al. Long-term anticoagulant therapy. Circulation. 1954;9(5):748-57.

17. Schulman S. Care of patients receiving long-term anticoagulant therapy. New England Journal of Medicine, 2005;349(7):675-83.

18. Lagerstedt C, Fagher B, Olsson CG, et al. Need for longterm anticoagulant treatment in symptomatic calf-vein thrombosis. The Lancet. 1985;326(8454):515-18.

19. Beauregard KM, Carper K. Outpatient prescription anticoagulants utilization and expenditures for the U.S. civilian noninstitutionalized population age 18 and older, 2007. Agency for healthcare research and quality. 2009.

20. Ansell J, Hirsh J, Poller L, et al. The pharmacology and management of the vitamin $\mathrm{K}$ antagonists: the Seventh ACCP Conference on Antithrombotic and Thrombolytic Therapy. Chest. 2004;126(3):S204-33

21. Barrett YC, Wang Z, Frost C, et al. Clinical laboratory measurement of direct factor Xa inhibitors: anti-Xa assay is preferable to prothrombin time assay. Thromb haemost. 2010;103(06):1263-71.

22. Samama MM, Martinoli JL, LeFlem L, et al. Assessment of laboratory assays to measure rivaroxaban-an oral, direct factor Xa inhibitor. Thromb haemost. 2010;104(04):815-25.

23. Perzborn E, Roehrig S, Straub A, et al. The discovery and development of rivaroxaban, an oral, direct factor Xa inhibitor. Nat Rev Drug Discov. 2011;10(1):61.

24. Connolly SJ, Ezekowitz MD, Yusuf S, et al. Dabigatran versus warfarin in patients with atrial fibrillation. $\mathrm{N}$ Engl J Med. 2009;361(12):1139-51.

25. Wells PS, Prins MH, Levitan B, et al. Long-term anticoagulation with rivaroxaban for preventing recurrent VTE: a benefit-risk analysis of EINSTEIN-extension. Chest. 2016;150(5):1059-68.

26. Dans AL, Connolly SJ, Wallentin L, et al. Concomitant use of antiplatelet therapy with dabigatran or warfarin in the Randomized Evaluation of Long-Term Anticoagulation Therapy (RE-LY) trial. Circulation. 2013;127(5):634-40.

27. Southworth SR, O'malley NP, Ebraheim NA, et al. Compartment syndrome as a presentation of non-Hodgkin's lymphoma. J Orthopaedic Trauma, 1990;4(4):47 and 473.

28. Trumble T. (1987). Forearm compartment syndrome secondary to leukemic infiltrates. J Hand Surg. 1987;12A(4):563-5.

29. Ojike NI, Roberts CS, Giannoudis PV. Compartment syndrome of the thigh: a systematic review. Injury. 2010;41(2):133-6.

30. Schwartz JT, Brumback RJ, Latakos R, et al. Acute compartment syndrome of the thigh. A spectrum of injury. J Bone Joint Surg Am. 1989;71:392-400.

31. Nadeem RD, Clift BA, Martindale JP, et al. (1998). Acute compartment syndrome of the thigh after joint replacement with anticoagulation. J Bone Joint Surg Br. 1998;80(5):866-8.

32. Pechar J, Lyons MM. Acute compartment syndrome of the lower leg: a review. J Nurse Pract. 2016;12(4):265-270.

33. Elliott KG, Johnstone AJ. Diagnosing acute compartment syndrome. J Bone Joint Surg Br. 2003;85(5):625-2.

34. Olson SA, Glasgow RR. Acute compartment syndrome in lower extremity musculoskeletal trauma. J Am Acad Orthop Surg. 2005;13(7):436-444.

35. Gourgiotis S, Villias C, Germanos S, et al. (2007). Acute limb compartment syndrome: a review. J Surg Educ. 2007;64(3):178-186.

36. Rush DS, Frame SB, Bell RM, et al. Does open fasciotomy contribute to morbidity and mortality after acute lower extremity ischemia and revascularization? J Vasc Surg. 1989;10(3):433-50

37. Jensen SL, Sandermann J. Compartment syndrome and fasciotomy in vascular surgery. A review of 57 cases. Eur J Vasc Endovasc Surg. 1997;13(1):48-53.

38. Kalyani BS, Fisher BE, Roberts CS, et al. (2011). Compartment syndrome of the forearm: a systematic review. J Hand Surg. 2011;36(3):535-43.

39. Heemskerk J, Kitslaar P. Acute compartment syndrome of the lower leg: retrospective study on prevalence, technique, and outcome of fasciotomies. World J Surg. 2003;27(6):744-47.

40. OjikeNI,RobertsCS, GiannoudisPV.Compartmentsyndrome of the thigh: a systematic review. Injury. 2010;41(2):133-136.

41. Roberge RJ, McLane M. Compartment syndrome after simple venipuncture in an anticoagulated patient. J Emerg Med. 1999:17(4);647-649.

42. Tiwari A, Haq AI, Myint F, et al. Acute compartment syndromes. Br J Surg. 2002;89(4):397-412.

43. Via AG, Oliva F, Spoliti M, et al. Acute compartment syndrome. Muscles Ligaments Tendons J. 2014;5(1):18.

44. Baker RI, Coughlin PB, Gallus AS, et al. Warfarin reversal: consensus guidelines on behalf of the Australasian Society of Thrombosis and Haemostasis. Med J Aust. 2004;181(9):492-97.

\section{*Correspondence to:}

\section{Nabil Ebraheim MD}

Department of Orthopaedic Surgery

University of Toledo College of Medicine and Life

Sciences

Toledo

Ohio

USA

Tel: 419-383-6158

E-mail: nabil.ebraheim@utoledo.edu 